\title{
PEMBERDAYAAN MASYARAKAT MELALUI PELATIHAN PEMBUATAN PUPUK ORGANIK CAIR UNTUK MENINGKATKAN PEREKONOMIAN PETANIDI DESA SIDOREJO KABUPATEN LAMONGAN
}

\author{
Diah Ayu Novitasari ${ }^{1}$, Indah Kurniawati ${ }^{2}$ \\ ${ }^{1}$ Jurusan Manajemen, Fakultas Ekonomi, Universitas Islam Lamongan \\ ${ }^{2}$ Jurusan Akuntansi, Fakultas Ekonomi, Universitas Islam Lamongan \\ J1. Veteran No.53A Lamongan \\ diahayu@unisla.ac.id ${ }^{1}$, indahkurniyawati@unisla.ac.id ${ }^{2}$
}

\begin{abstract}
ABSTRAK
Pupuk organik cair (POC) salah satu pupuk organik yang sangat dibutuhkan oleh masyarkat dan popular di kalangan masyarakat. POC dibutuhkan masyarakat karena harganya yang relatif murah dan lebih ramah lingkungan. Namun masyarakat belum banyak yang tahu bahwa pembuatan POC sangat mudah dan bisa dilakukan oleh individu rumah tangga. Pelatihan pembuatan POC ini dilakukan atas permintaan warga masyarakat Desa Sidorejo. Pelatihan dilakukan pada 24 Juli 2019 dengan peserta warga Desa Sidorejo Kecamatan Deket Kabupaten Lamongan. Tujuan pelatihan ini adalah agar warga Desa Sidorejo dapat membuat sendiri POC dan dapat mengembangkan menjadi usaha untuk meningkatkan pendapatan warga Desa. Analisis Kelayakan Usaha Pembuatan POC didapatkan bahwa nilai ROI adalah 19,047\%. Hal ini berarti usaha pembuatan POC dapat menghasilkan pendapatan $19,047 \%$ dari biaya investasi yang dikeluarkan.
\end{abstract}

Kata Kunci : Pemberdayaan masyarakat, Pupuk organik cair, bisnis pertanian.

\begin{abstract}
Liquid Organic Fertilizer (POC) is an organic fertilizer that is highly needed by the community and is popular among the people. POC is needed by the community because the price is relatively cheap and more environmentally friendly. But not many people know that making POC is very easy and can be done by individual households. This POC manufacturing training was carried out at the request of the community members of Sidorejo Village. The training was conducted on July 24, 2019 with participants from Sidorejo Village, Deket Subdistrict, Lamongan Regency. The purpose of this training is that the people of Sidorejo Village can make their own POC and can develop into an effort to increase the income of the villagers. Business Feasibility Analysis of POC Making found that the ROI value is $19.047 \%$. This means that the business of making POC can generate income of $19,047 \%$ of the investment costs incurred.
\end{abstract}

Key words: community empowerment, liquid organic fertilizer, agricultural business.

\section{PENDAHULUAN}

Petani di Indonesia biasanya menggunakan pupuk kimia untuk membantu proses produksi tanaman pertaniannya. Namun, pupuk kimia tersebut ternyata memberi dampak buruk 
terhadap tanah pertanian. Hal ini membuat petani di Indonesia mencari pupuk alternatif lain yang lebih ramah terhadap tanah dan lingkungan yaitu pupuk organik cair (POC). Pupuk organik cair adalah pupuk organik cair yang dihasilkan dari bahan-bahan organik dan ramah lingkungan. POC sangat baik digunakan pada bidang pertanian, perkebunan, padang golf dan tanaman hias. Pupuk organik adalah pupuk yang berperan dalam meningkatkan aktivitas biologi, kimia, dan fisik tanah sehingga tanah menjadi subur dan baik untuk pertumbuhan tanaman (Indriani, 2004)

Pupuk POC dapat memperbaiki struktur tanah yang rusak akibat pupuk kimia. Pupuk organik ini sangat dibutuhkan oleh para petani untuk meningkatkan hasil pertaniannya dan meningkatkan produksi tanamannya di perkebunan.

Beberapa tahun terakhir pengunaan POC mengalami peningkatan yang signifikan. Hal ini didasari dengan semakin banyaknya permintaan POC di pasar pertanian Indonesia, begitu juga dengan petani di Desa Sidorejo. Pembuatan POC ini sangat mudah dan bahan yang dibutuhkan juga mudah dicari. Namun pembuatannya tetap diperlukan pendampingan dari tenaga ahli di bidang pertanian. POC ini juga dapat dijadikan lahan bisnis dengan omset yang menjanjikan. Bisnis POC menghemat biaya produksi dan dapat meningkatkan hasil produksi pertanian. Selain itu, pangsa pasar POC sangat besar karena lahan pertanian di Indonesia sangat luas. Hal inilah yang mendasari dibuat pelatihan pembuatan POC untuk memberdayakan petani dan untuk meningkatkan perekonomian di Desa Sidorejo Kabupaten Lamongan.

\section{METODE PENELITIAN}

Pelatihan ini diadakan di Desa Sidorejo Kabupaten Lamongan bekerjasama dengan perangkat desa dan Mahasiswa Universitas Islam Lamongan sebagai pemateri.

Alat-alat yang diperlukan untuk pembuatan POC adalah sebagai berikut :

1. Alat penghalus (Blender / lumpang)

2. Drum plastik ukuran 50 -100 liter

3. Alat pengaduk (kayu/bambu)

4. Ember, dll

Bahan-bahan yang diperlukan untuk pembuatan POC dibagi menjadi dua, yaitu dari limbah dan bukan limbah. Bahan yang berasal dari limbah dijelaskan dalam Tabel 1 sebagai berikut : 
Tabel 1. Bahan-Bahan pembuatan POC dari Limbah

\begin{tabular}{|l|l|}
\hline Bahan & Jumlah \\
\hline Air cucian daging & 5 liter \\
\hline Air cucian ikan & 5 liter \\
\hline Isi usus ternak & 500 gram \\
\hline Air urine ternak / manusia & 5 liter \\
\hline $\begin{array}{l}\text { Coco dust (beras sabut } \\
\text { kelapa) }\end{array}$ & $1 \mathrm{~kg}$ \\
\hline $\begin{array}{l}\text { Kotoran ayam/kambing/dll } \\
\text { Tanah dari bawah pohon } \\
\text { bambu }\end{array}$ & $2 \mathrm{~kg}$ \\
\hline $\begin{array}{l}\text { Isi tembolok ayam/unggas } \\
\text { lainnya }\end{array}$ & $0,5 \mathrm{~kg}$ \\
\hline
\end{tabular}

Tabel 2. Bahan-Bahan pembuatan POC dari Bukan Limbah

\begin{tabular}{|l|l|}
\hline Bahan & Jumlah \\
\hline Alkhohol 40\% & $500 \mathrm{cc}$ \\
\hline Cuka & $500 \mathrm{cc}$ \\
\hline Gula Merah & 200 gram \\
\hline $\begin{array}{l}\text { MOL (Micro Organisme } \\
\text { Lokal) }\end{array}$ & $500 \mathrm{cc}$ \\
\hline Daging buah gerenuk & $2 \mathrm{~kg}$ \\
\hline $\begin{array}{l}\text { Parudan rebung/bambu } \\
\text { muda }\end{array}$ & $2 \mathrm{~kg}$ \\
\hline Jahe & 100 gram \\
\hline Laos & 100 gram \\
\hline Kencur & 100 gram \\
\hline Kunir & 100 gram \\
\hline Bangle & 100 gram \\
\hline $\begin{array}{l}\text { Merica dan ketumbar } \\
\text { (halus) }\end{array}$ & $\begin{array}{l}\text { makan sendok } \\
\text { maka }\end{array}$ \\
\hline
\end{tabular}




\section{Tabel 2. Lanjutan Bahan-Bahan pembuatan POC dari Bukan Limbah}

\begin{tabular}{|l|l|}
\hline Bahan & Jumlah \\
\hline Cengkeh/daunnya & 100 gram \\
\hline $\begin{array}{l}\text { Sereh, daun salam dan } \\
\text { honje }\end{array}$ & @ 50 gram \\
\hline Bawang merah & 100 gram \\
\hline Bawang putih & 100 gram \\
\hline
\end{tabular}

Langkah-langkah pembuatan POC adalah sebagai berikut:

1. Siapkan bahan-bahan yang diperlukan untuk pembuatan POC baik dari limbah maupun bahan yang bukan dari limbah

2. Siapkan tong plastik kedap udara ukuran 100 liter sebagai media pembuatan pupuk, satu meter selang aerotor transparan (diameter kira-kira $0,5 \mathrm{~cm}$ ), botol plastik bekas air mineral ukuran 1 liter. Lubangi tutup tong seukuran selang aerotor.

3. Masukkan bahan-bahan kedalam tong dan tambahkan air, komposisinya: 2 bagian bahan organik, 1 bagian air. Kemudian aduk-aduk hingga merata.

4. Larutkan bioaktivator seperti EM4 dan gula merah 5 liter air aduk hingga merata. Kemudian tambahkan larutan tersebut ke dalam tong yang berisi bahan baku pupuk.

5. Tutup tong plastik dengan rapat, lalu masukan selang lewat tutup tong yang telah diberi lubang. Rekatkan tempat selang masuk sehingga tidak ada celah udara. Biarkan ujung selang yang lain masuk kedalam botol yang telah diberi air.

6. Pastikan benar-benar rapat, karena reaksinya akan berlangsung secara anaerob. Fungsi selang adalah untuk menyetabilkan suhu adonan dengan membuang gas yang dihasilkan tanpa harus ada udara dari luar masuk ke dalam tong.

7. Tunggu hingga 7-10 hari. Untuk mengecek tingkat kematangan, buka penutup tong cium bau adonan. Apabila wanginya seperti wangi tape, adonan sudah matang.

8. Pisahkan antara cairan dengan ampasnya dengan cara menyaringnya. Gunakan saringan kain. Ampas adonan bisa digunakan sebagai pupuk organik padat.

9. Masukkan cairan yang telah melewati penyaringan pada botol plastik atau kaca, tutup rapat. Pupuk organik cair telah jadi dan siap digunakan. Apabila dikemas baik, pupuk bisa digunakan sampai 6 bulan. 


\section{HASIL DAN PEMBAHASAN}

Biaya investasi yang digunakan untuk pembuatan POC adalah sebagai berikut :

Tabel 3. Biaya Investasi pembuatan POC

\begin{tabular}{|c|c|c|c|}
\hline Komponen & Satuan & $\begin{array}{l}\text { Biaya } \\
\text { Satuan }\end{array}$ & $\begin{array}{l}\text { Jumlah } \\
\text { Biaya }\end{array}$ \\
\hline $\begin{array}{l}\text { Komposter, } \\
\text { biovaktor, } \\
\text { dan sprayer }\end{array}$ & $\begin{array}{l}1 \\
\text { paket }\end{array}$ & 200.000 & 200.000 \\
\hline $\begin{array}{l}\text { Gunting } \\
\text { atau pisau }\end{array}$ & 1 buah & 8.000 & 8.000 \\
\hline Wadah & 1 buah & 11.000 & 11.000 \\
\hline $\begin{array}{l}\text { Alat } \\
\text { Pengaduk }\end{array}$ & 1 buah & 12.000 & 12.000 \\
\hline \multicolumn{3}{|c|}{ Total Biaya Investasi } & 231.000 \\
\hline
\end{tabular}

Tabel 4. Biaya Investasi pembuatan POC

\begin{tabular}{|c|c|c|c|}
\hline Komponen & Satuan & $\begin{array}{l}\text { Biaya } \\
\text { Satuan }\end{array}$ & $\begin{array}{l}\text { Jumlah } \\
\text { Biaya }\end{array}$ \\
\hline $\begin{array}{l}\text { Ongkos } \\
\text { pemisahan } \\
\text { sampah } \\
\text { organik }\end{array}$ & $\begin{array}{l}1 \\
\text { paket }\end{array}$ & 4.000 & 4.000 \\
\hline $\begin{array}{l}\text { Ongkos } \\
\text { perajangan } \\
\text { sampah } \\
\text { organic }\end{array}$ & $\begin{array}{l}1 \\
\text { paket }\end{array}$ & 2.000 & 2.000 \\
\hline Air & 1 liter & 3.000 & 3.000 \\
\hline $\begin{array}{l}\text { Penyusutan } \\
\text { Peralatan }\end{array}$ & & & 22.000 \\
\hline \multicolumn{3}{|c|}{ Total Biaya Investasi } & 31.000 \\
\hline
\end{tabular}


Analisis usaha pembuatan POC adalah sebagai berikut :

Pendapatan 1 hari usaha pembuatan POC

$=$ Jumlah produksi $\mathrm{x}$ harga jual komposter $=2$ liter $\mathrm{x}$ Rp 22.000/liter $=\mathrm{Rp} 44.000$

Keuntungan 1 hari

$=$ Pendapatan - Biaya Produksi

$=\operatorname{Rp} 44.000-\operatorname{Rp} 31.000=\operatorname{Rp} 13.000$

Jika dalam satu bulan diasumsikan adalah 20 hari kerja, maka perhitungan keuntungan yang diperoleh selama satu bulan mencapai 20 x Rp 13.000 sehingga diperoleh keuntungan $\mathrm{Rp}$ 260.000

Analisis Kelayakan Usaha Pembuatan Komposter

Return of Investment (ROI)

ROI $=\frac{\text { Total Biaya Pendapatan }}{\text { Total Biaya Investasi }} \times 100 \%$

ROI $=\frac{R p 44.000}{R p 231.000} \times 100 \%$

ROI $=19,047 \%$

Hal ini menunjukkan bahwa usaha ini menghasilkan pendapatan 19,047\% dari total biaya investasi yang dikeluarkan.

Berdasarkan analisis diatas maka jika usaha ini dilakukan oleh rumah tangga dan juga seluruh warga Desa Sidorejo maka akan dapat meningkatkan pendapatan warga Desa Sidorejo.

\section{SIMPULAN}

Kesimpulan yang dihasilkan dari pengabdian masyarakat ini adalah sebagai berikut :

1. Masyarakat antusias terhadap pelatihan ini

2. Masyarakat sudah dapat mengaplikasikan pembuatan POC di rumah masing-masing

3. Masyarakat Desa Sidorejo sudah mulai memproduksi POC secara masal di tingkat RT.

4. Saran untuk pengabdian selanjutnya adalah pelatihan ini dapat dilakukan secara rutin dan dilakukan dengan skala yang lebih besar agar dapat memberikan manfaat yang lebih luas untuk masyarakat.

\section{DAFTAR PUSTAKA}

https://panduanbertanam.blogspot.com/2016/04/membuka-usaha-pembuatan-komposterdan.html (diakses tanggal 19 Agustus 2019)

https://alamtani.com/pupuk-organik-cair/ (diakses tanggal 19 Agustus 2019) 